\title{
Mitos kecantikan dan fenomena hijrah dalam novel Metropop Belok Kiri Langsing karya Achi TM
}

\section{Tania Intan}

Program Studi Sastra Perancis, Fakultas Ilmu Budaya, Universitas Padjadjaran, Jl. Raya Bandung-Sumedang Km. 2I,7 Jatinangor, Indonesia

tania.intan@unpad.ac.id

*Corresponding author: tania.intan@unpad.ac.id

\begin{tabular}{|c|c|c|}
\hline & & \\
\hline \multicolumn{3}{|c|}{ ABSTRAK } \\
\hline \multicolumn{3}{|c|}{$\begin{array}{l}\text { Ideologi patriarki mengintimidasi perempuan dengan jalan yang terorganisir } \\
\text { mendefinisikan konsep 'cantik'. Penelitian ini bertujuan untuk mengungka } \\
\text { dampaknya pada perempuan, serta fenomena hijrah, sebagai tema sekunder, ya } \\
\text { Langsing (2020) karya Achi TM. Penelitian ini menerapkan metode deskripti } \\
\text { sastra feminis. Data berupa kata, frasa, dan kalimat dikumpulkan dengan teknik } \\
\text { selanjutnya dikategorisasi, diinterpretasi, dan dianalisis dengan teori-teori yang } \\
\text { kecantikan diciptakan oleh patriarki untuk mengontrol tubuh perempuan. Mit } \\
\text { karena selalu disosialisasikan, juga karena ambivalensi karakter perempuan yan } \\
\text { membawa dampak pada imaji ideal perempuan, pelecehan tubuh, dan kom } \\
\text { terdiskriminasi dan terobsesi pada tubuh. Sementara itu, fenomena hijrah sec } \\
\text { berupa standar 'perempuan islami. Dari penelitian ini, terungkap adanya } \\
\text { tentang idealisasi perempuan dan tubuhnya. Kecantikan fisik berupa tub } \\
\text { yang ideal tidak seharusnya mengikat dan menyudutkan perempuan. }\end{array}$} \\
\hline \multirow{2}{*}{\multicolumn{3}{|c|}{ Fenomena hijrah, Kritik sastra feminis, Metropop, Mito }} \\
\hline & & \\
\hline \multicolumn{3}{|c|}{$\begin{array}{l}\text { Patriarchal ideology intimidates women in an organized way through va } \\
\text { concept of 'beauty'. This study aimed to reveal the mythical forms of b } \\
\text { well as the phenomenon of hijrah, as the secondary theme, which is feat } \\
\text { Langsing ( } 2020 \text { ). This study applied a descriptive method, while the a } \\
\text { data in the form of words, phrases, and sentences were collected using th } \\
\text { reading. The data were then categorized, interpreted, and analyzed wit } \\
\text { myth of beauty is created by patriarchy to control women's bodies. The } \\
\text { apart from being constantly socialized, but also because of the ambivalen } \\
\text { her body. Beauty myths also give an impact on the ideal image of women } \\
\text { them constantly discriminated against and obsessed with the body. Mea } \\
\text { birth to a new beauty myth in the form of 'Islamic women' standards. } \\
\text { incomplete perception of a patriarchal society about the idealization of } \\
\text { form of a slim body which is socialized as an ideal should not constrain }\end{array}$} \\
\hline & & \\
\hline & \multicolumn{2}{|c|}{ Phenomenon of hijrah, Feminist literary criticism, Metropop, Beauty myth, Women } \\
\hline & \multicolumn{2}{|c|}{$\begin{array}{l}\text { Intan, T. (202I). Mitos kecantikan dan fenomena hijrah dalam novel Metropop Belok Kiri Langsing } \\
\text { karya Achi TM. KEMBARA: Jurnal Keilmuan, Bahasa, Sastra dan Pengajarannya (e-Journal), 7(I), } \\
\text { I I8-I30. doi: https://doi.org/I0.222I9/kembara.v7iI. I56I4 }\end{array}$} \\
\hline
\end{tabular}

\section{PENDAHULUAN}

Pada umumnya, tokoh perempuan yang ditampilkan di dalam karya fiksi populer seperti chicklit, teen-lit, maupun metropop memiliki wajah yang rupawan dan tubuh yang langsing. Namun, saat ini dapat ditemukan sejumlah novel yang mengeksplorasi cerita tentang tokoh perempuan bertubuh gemuk, 
seperti dalam novel Holding $U_{p}$ the Universe (2018) karya Jennifer Niven, Dumplin (2019) karya Julie Murphy, Kilovegram (2018) karya Mega Shofani, Gendut? Siapa Takut! (2019) karya Alnira, dan The Princess in Me (2005) karya Dona Rosamayna. Hal ini memperlihatkan bagaimana tubuh [perempuan] merupakan lahan yang potensial untuk dibincangkan dan dipelajari.

Dalam penelitian ini, objek yang telah dipilih adalah metropop Belok Kiri Langsing (2020) karya Achi TM. Metropop adalah abreviasi dari 'metropopular' yang merujuk pada setting dan isu permasalahan masyarakat urban, seperti cinta, karier, dan kehidupan (Arimbi, 2017). Novel tersebut menampilkan protagonis perempuan berusia 29 tahun yang bertubuh gemuk bernama Gendis Utami. Karena berat badannya yang berlebih itulah, perempuan yang lima tahun sebelumnya sangat langsing itu kini dipanggil 'Gendut' oleh teman-teman di tempatnya bekerja. Sebagai penulis, Achi TM telah menciptakan lebih dari 20 karya novel dan ratusan skenario sinetron televisi (Hatmoko, 2019). Ia lahir di Jakarta pada tanggal 3 April 1985. Karya-karyanya yang lain di antaranya Insya Allah SAH dan Cincin Lama Belum Kembali. Dari wawancara yang dilakukan terhadap Achi TM, diketahui bahwa dirinya pernah melakukan beragam diet ketat yang menyiksa demi menurunkan berat badan, sehingga apa yang dialami tokoh Gendis merupakan gambaran dari pengalamannya sendiri.

Kegemukan pada perempuan merupakan isu kehidupan urban yang berkaitan dengan kesehatan dan kecantikan. Dalam kajiannya, Nasution (2015) mengargumentasikan bagaimana menjadi gemuk adalah fakta natural pada tubuh. Namun, lingkungan sekitar berpotensi mengajukan fakta sosial bahwa tubuh yang gemuk bukan tubuh yang ideal, berbeda misalnya dengan dekade tahun I960-an, ketika tubuh yang gemuk diapresiasi sebagai simbol kemakmuran, keidealan, dan kesehatan. Hal ini menunjukkan bahwa tubuh individual dapat dimaknai berbeda, sehingga mengalami diferensiasi sesuai dengan kehendak kekuatan sosial. Keluarnya tubuh dari konvensi bersama yang menuntutnya untuk menjadi langsing, membuat individu penyandangnya rentan menerima stigma sebagai pelanggaran yang menghendaki alienasi diri.

Penyebab dari situasi tersebut, menurut Arimbi (2013), adalah karena perempuan sering menjadi objek atau bahkan korban dari bayangan utopis yang ditampilkan media seperti iklan, yang menampilkan perempuan yang rupawan, cantik, dan manja yang tidak lain merupakan ilusi kosong. Selain konstruksi tubuh tersebut, perempuan juga terperangkap dalam stereotipe sebagai makhluk yang terobsesi dengan kecantikan, lemah lembut, bodoh, dan hanya memiliki harga separuh saja dari laki-laki. Pembenaran atas konsep kecantikan yang diatur oleh laki-laki itu menciptakan standar baru yang disebut dengan mitos kecantikan (Wolf, 2004). Priyatna (2018) berargumentasi bahwa wacana kecantikan dan femininitas perempuan memang tidak dapat dilepaskan dari konstruksi budaya patriarki yang memberi laki-laki kuasa untuk memberikan pengakuan atas femininitas perempuan. Di sisi lain, perempuan sendiri selalu mencari pengakuan atas femininitasnya dari laki-laki. Dengan demikian, apa yang ditampilkan perempuan melalui tubuhnya adalah gambaran yang ingin dilihat oleh laki-laki.

Perhatian perempuan terhadap tubuhnya dan konstruksi media tentang tubuh langsing sebagai tubuh ideal dan sempurna membuat perempuan cenderung tidak percaya diri (Natha, 2017). Hal ini terjadi, karena menurut Mulyana (2005), cara perempuan menilai tubuhnya sangat berkaitan dengan bagaimana lingkungan sosial dan budaya di luar dirinya menilai tubuh perempuan. Menurut Wolf (2004), rasa sakit dan kecemasan perempuan itulah yang menjadi bahan baku utama yang ditawarkan oleh mitos kecantikan. Dengan konstruksi kultural tersebut, perempuan diyakinkan bahwa kualitas yang disebut 'cantik' itu benar-benar ada, objektif, dan universal. Pada kenyataannya, konsep kecantikan selalu berubah dan tidak ada batasan yang standar (Anugrah, 2015).

Penelitian terdahulu yang membahas tubuh perempuan dan mitos kecantikan dalam konteks psikologis di antaranya telah dilakukan Sakinah (2018). Kajian tersebut menemukan bahwa standar tubuh yang ideal menjadikan seseorang menilai terhadap tubuhnya sendiri (body image) dan terhadap orang lain. Jika tidak sesuai dengan standar ideal yang berlaku, kondisi yang mungkin terjadi adalah rasa malu dan potensi menjadi objek body shaming. Body shaming yang dialami dapat terjadi dalam dua kategori yaitu verbal serta kombinasi antara verbal dan tindakan. Perundungan secara verbal ini dapat 
dikategorikan sebagai kekerasan berbasis gender, yang seringkali mengintimidasi pihak yang lemah seperti perempuan (Arista, 2017).

Kajian terhadap permasalahan mitos kecantikan di dalam teks fiksi telah dilakukan oleh Julian (2016), Kurnianto (20I4), dan Anugrah (2015). Julian (2016) mengangkat isu mitos kecantikan di dalam cerpen-cerpen karya Dwi Ratih Ramadhany dengan landasan teoretis dari Wolf. Pada teks yang dikaji, ditemukan bahwa standar baku kecantikan perempuan adalah rambut hitam panjang, leher jenjang, bibir merekah, tubuh yang wangi, kulit kencang-putih-mulis, dan langsing. Penelitian ini juga membuktikan bahwa dalam wacana gender, kecantikan berhubungan dengan industri patriarki, kontestasi antarperempuan, dan industri kapitalistik. Telaah terhadap representasi tubuh dan kecantikan juga dilakukan Kurnianto (2014) terhadap tiga cerpen karya Intan Paramaditha. Dengan menggunakan teori Lévy Strauss, Barthes, dan Foucault, dari kajian tersebut terungkap bahwa perempuan tidak memiliki kekuasaan atas diri [tubuh]nya sendiri. Konstruksi patriarki tentang nilai 'cantik' atau 'tidak cantik' membuat perempuan pun menjadi liyan. Konstruksi tersebut diperkuat oleh sifat ambivalen perempuan tentang tubuh dan kecantikannya.

Kelindan di antara mitos kecantikan dan perilaku konsumtif sebagai bagian dari budaya konsumen diperlihatkan melalui penelitian Anugrah (2015), Intan dan Mariamurti (2019), serta Aini (2018). Kajian Anugerah tersebut menunjukkan relasi antara mitos kecantikan dengan aspek lain, yaitu budaya patriarki, industri kosmetik, dan dunia medis estetis. Pengaruh dari mitos kecantikan pada perempuan adalah diskriminasi, obsesi, dan keputusan untuk melakukan operasi plastik. Dalam kajiannya, Intan dan Mariamurti menemukan bahwa budaya konsumen yang dihayati para tokoh perempuan merupakan dampak dari mitos kecantikan dan didasari oleh motivasi untuk dipandang lakilaki, tuntutan dari pekerjaan, serta hasrat ambivalen perempuan untuk selalu tampil muda. Hal ini selaras dengan penelitian Aini (2018) yang mengindikasikan bahwa mitos kecantikan, yang merupakan upaya patriarki untuk mengendalikan perempuan melalui tubuhnya, juga dapat dimaknai dalam konteks kepentingan industri. Selain mendorong perempuan untuk menjadi konsumtif, mitos kecantikan juga dianggap tidak relevan dengan konsep perempuan sholihah dalam agama Islam.

Selain permasalahan pandangan terhadap tubuh perempuan yang diakibatkan oleh mitos kecantikan, isu lain yang juga mengemuka di dalam novel Belok Kiri Langsing adalah fenomena hijrah. Dalam kajian Musahadah dan Triyono (2019), secara kebahasaan hijrah berarti 'berpindah', dalam arti 'berubah menjadi pribadi yang lebih baik dan religius'. Dengan mengutip As'ad, Fajriani dan Sugandi (2019) menguraikan bahwa hijrah beralih makna dari peristiwa kepindahan Nabi Muhammad SAW dan pengikutnya ke Madinah menjadi berkonteks kultural. Seseorang yang hijrah pada masa kini berarti menjauhi perilaku buruk agar memperoleh gaya hidup yang lebih islami. Keputusan berhijrah pun pada umumnya dilakukan oleh masyarakat kelas menengah yang cukup berpendidikan dan secara ekonomi lebih mapan. Hijrah juga kerap disosialisasikan melalui media sosial.

Kajian tentang fenomena hijrah baik di dalam novel maupun dalam situasi nyata telah dibahas di antaranya oleh Musahadah dan Triyono (2019), yang mempelajari cara penyampaian ajakan yang bersifat persuasif untuk hijrah di dalam media Instagram. Artikel tersebut menggunakan metode analisis wacana kritis van Djick dengan teknik baca markah. Hasil penelitian menunjukkan bahwa persuasi dilakukan melalui cara retoris langsung, tidak langsung, hadis, doa, atau harapan, cerita, ekspresi, majas, dan repetisi. Sementara itu, Fajriani dan Sugandi (2019) mendeskripsikan perkembangan hijrah islami milenial dengan pendekatan studi kepustakaan. Kajian ini di antaranya menemukan banyaknya publik figur perempuan muslim yang menggunakan hijab dan para artis yang mengikuti kegiatan kajian. Hijrah islami milenial juga terungkap melalui ekspresi yang ditunjukkan melalui gagasan yang maju serta pola pikir yang lebih kritis dan terbuka. Hijrah dianggap sebagai gerakan sosial baru yang terjadi pada masyarakat milenial sebagai penguat identitas umat Islam. Gagasan serupa ditemukan Lyansari (2018) yang meneliti tiga selebriti Indonesia yang menyatakan diri hijrah. Dari penelitian terhadap media sosial dan buku yang ditulis ketiga selebriti tersebut, terungkap bahwa proses hijrah mengubah pola pikir mereka dan menciptakan gaya hidup baru. 
Sholihah (2019) meneliti trend berhijrah di kalangan muslim milenial dan kemudian membandingkannya dengan hijrah di dalam kitab-kitab dari masa lalu. Penelitian tersebut menemukan bahwa pada umumnya hijrah yang dilakukan muslim milenial masih terbatas pada kesalihan fisik dan belum benar-benar menyentuh hakikatnya. Bersepakat dengan pandangan tersebut, Addini (2019) mengungkapkan bahwa di tengah kepopulerannya, perilaku hijrah saat ini seperti kehilangan makna substansi asalnya dan hanya dipandang sebagai peralihan secara simbolik. Hijrah sejatinya bukan hanya penguatan nilai-nilai keagamaan, melainkan misi reformasi pada setiap sendi kehidupan, baik sosial, ekonomi, maupun politik.

Dalam penelusuran peneliti, kajian terhadap novel-novel karya Achi TM belum banyak ditemukan. Hanya ada dua karya yang telah diteliti, yaitu Bisikan Sahabat oleh Diba (2014) dan Di Batas Pelangi oleh Silfia dkk. (2018) yang menggunakan pendekatan sosiologi sastra untuk mempelajari gejala kehidupan masyarakat dan permasalahan sosial di dalam novel yang dikaji. Tidak ditemukan penelitian terdahulu terhadap Belok Kiri Langsing yang merupakan karya terbaru dari pengarang tersebut. Pembahasan tentang tubuh [perempuan] yang gemuk sebagai isu feminis pun belum banyak dilakukan (Fikkan, 2012). Demikian pula halnya dengan penelitian yang menautkan mitos kecantikan pada fenomena hijrah dalam novel. Oleh karena itu, berbeda dengan penelitian-penelitian terdahulu, kajian ini dapat dianggap memiliki nilai kebaruan sehingga dapat berkontribusi dalam melengkapi pembahasan tentang mitos kecantikan dan fenomena hijrah dalam karya sastra yang sangat relevan dengan situasi saat ini. Untuk membatasi wilayah kajian, tujuan penelitian yang dirumuskan dalam penelitian ini adalah (a) mengungkap bentuk-bentuk mitos kecantikan, cara kerja, dan dampaknya pada perempuan, serta (b) fenomena hijrah yang ditampilkan di dalam novel metropop Belok Kiri Langsing karya Achi TM.

\section{METODE}

Penelitian ini menerapkan metode deskriptif-kualitatif. Menurut Moleong (2012), dalam metode deskriptif, data yang dikumpulkan berupa kata-kata atau gambar dan bukan angka-angka. Pendekatan kritik sastra feminis digunakan dengan mengaplikasikan teori-teori yang berhubungan dengan gerakan perempuan, karena sastra feminis berakar dari pemahaman tentang inferioritas perempuan dan konsep kunci feminis adalah kesetaraan perempuan dan laki-laki. Pendekatan tersebut bertujuan membongkar kekuasaan laki-laki atas perempuan dan menempatkan perempuan [kembali] pada posisi yang seharusnya, yaitu sejajar dengan laki-laki (Anggraini, 2016). Karena penelitian ini berperspektif feminis, maka sebagaimana dinyatakan Klein, metodologi yang digunakan harus ditujukan untuk perempuan, bermanfaat untuk perempuan, dan memungkinkan adanya subjektivitas sadar pada perempuan dalam mempelajari perempuan (Humm, 2007).

Data berupa kata, frasa, dan kalimat yang berkaitan dengan permasalahan yang dibincangkan, yaitu fenomena hijrah dan mitos kecantikan, dikumpulkan dari novel Belok Kiri Langsing dengan teknik simak catat setelah melalui pembacaan tertutup. Janicke, dalam Nugraha dan Suyitno (2019), mendefinisikan pembacaan tertutup sebagai "interpretasi menyeluruh dari suatu bagian teks dengan penentuan tema sentral dan analisis perkembangannya”. Studi kepustakaan ini dilakukan dengan menelaah referensi yang sesuai dengan permasalahan penelitian, yaitu mitos kecantikan dan fenomena hijrah. Data selanjutnya dikategorisasi, diinterpretasi, dan dianalisis dengan teori-teori yang relevan serta dibandingkan dengan penelitian terdahulu. Pada bagian terakhir, simpulan dirumuskan sebagai temuan penelitian.

Novel yang dipilih sebagai objek penelitian adalah metropop berjudul Belok Kiri Langsing karya Achi TM (2020). Novel yang diterbitkan oleh PT. Gramedia Pustaka Utama ini adalah karyanya yang ke-36. Judul Belok Kiri Langsing tersebut secara sepintas dapat mengingatkan pembaca pada istilah informal 'bekibolang' atau 'belok kiri [boleh] langsung' yang merupakan salah satu peraturan lalu lintas. Namun, dalam novel tersebut, judul merujuk pada metafora pergerakan jarum timbangan tubuh yang mengarah ke sebelah kiri yang menunjukkan adanya penurunan berat badan. 


\section{HASIL DAN PEMBAHASAN \\ Ringkasan Cerita}

Novel Belok Kiri Langsing dinarasikan oleh pencerita orang pertama oleh tokoh Gendis yang menyebut dirinya 'aku'. Konsekuensi dari penceritaan seperti ini adalah narasi yang subjektif, terbatas pada apa yang diketahui narator, dan bersifat pengakuan. Sebagai tokoh dengan karakter yang humoris sekaligus emosional, Gendis menyampaikan secara lantang observasi tentang kisah percintaannya dengan Herman, dan kemudian dengan Dimas. Latar tempat yang mendominasi kisah ini adalah kantor yang merupakan ruang bertemunya para tokoh, sehingga metropop ini dapat dikategorikan sebagai romanceoffice.

Gendis Utami adalah seorang perempuan berumur 29 tahun yang bekerja sebagai administrasi umum di sebuah perusahaan perlengkapan kantor. Ia biasa dipanggil 'Gendut' oleh teman-teman kantornya, yang merupakan gabungan dari namanya 'Gend-Ut', sekaligus gambaran atas bentuk tubuhnya. Gendis tidak pernah menyangka akan diputuskan oleh Herman setelah mereka berpacaran selama lebih dari lima tahun. Selama ini, ia merasa sangat yakin akan menjadi istri laki-laki itu terlebih setelah mereka mencicil rumah bersama. Sebagai seorang perempuan yang memiliki pandangan tradisional, Gendis bercita-cita untuk segera berumah tangga, terlebih usianya telah mencapai 29 tahun.

Herman meninggalkan perempuan dengan bobot $106 \mathrm{~kg}$ itu karena, menurutnya, sekarang Gendis menjadi sangat gemuk, boros, dan pemalas. Herman juga takut bila Gendis sulit memiliki anak. Selain itu, Herman bermaksud untuk melakukan 'hijrah' sehingga tidak ingin berpacaran lagi dan memilih untuk segera menikahi gadis idamannya. Putusnya hubungan di antara Gendis dan Herman ini terjadi di restoran Geprek Couple yang disaksikan oleh Dimas Adinegara, pemilik tempat itu. Laki-laki yang langsing dan tampan mirip dengan penyanyi Cha Eun Woo tersebut ternyata pernah dihina oleh Gendis lima tahun yang lalu karena tubuhnya sangat gemuk.

Pada awalnya, Dimas senang melihat perempuan yang dulu menghinanya kini berada pada posisinya yang terpuruk lima tahun yang lalu. Namun, kemudian Dimas merasa bersalah karena pernah mendoakan Gendis segemuk dirinya hingga memukuli foto perempuan itu yang ditempel pada samsak. Dimas pun memutuskan untuk membantu perempuan itu menurunkan berat badan dengan cara mendaftarkannya pada sanggar yoga, menyuplay buah-buahan dan makanan sehat, mengajaknya berolahraga, serta memotivasi Gendis untuk lebih memperhatikan kesehatan tubuhnya.

Fenomena hijrah diperlihatkan melalui tokoh-tokoh dalam novel dengan latar kota Jakarta ini. Gendis mulai berhijab setelah sekian lama mengumpulkan niat dan sejumlah jilbab di dalam lemarinya. Herman sendiri memutuskan Gendis dengan alasan tidak ingin pacaran dan memilih untuk langsung menikah untuk menghindari zina. Dimas berhijrah dengan menunjukkan perilaku menjaga adab dalam kesehariannya termasuk dalam hubungannya dengan para perempuan.

\section{Perempuan dan Ketidakpuasan atas Tubuhnya}

Perasaan waswas perempuan karena kenaikan berat badan, wajah yang berkerut, atau rambut yang tidak mudah diatur, sebenarnya menunjukkan betapa tidak netralnya tubuh, karena ditentukan dan dikendalikan oleh kekuatan di luar dirinya. Kuasa tersebut begitu detail mengonstruksi tubuh perempuan, sehingga mendeterminasi peran biologis dan sosialnya. Demikian tidak netralnya tubuh perempuan, hingga untuk mendefinisikan kata cantik pun perempuan harus mengafirmasi imajinasi dan standar-standar yang diatur oleh laki-laki. Sebagaimana dinyatakan Wolf yang dikutip Anugrah (2015), "[...] mitos kecantikan menumbuhkan anggapan bahwa perempuan adalah makhluk yang 'sakit' dan mereka akan menjadi 'pasien' yang memberikan keuntungan di mana pun ditemukan perempuan dari kelas menengah.”

"Kondisimu bikin aku takut punya anak. Dan aku takut salah pilih istri. Aku takut saat kita punya anak, kamu malah terkena stroke karena darah tinggi. Atau yang paling pahit adalah ... aku bakal susah punya anak karena cewek gendut susah hamil, Gen." $[\ldots]$

"Makanya aku nggak mau gendut dan nggak mau ketularan gendut." 
"Gendut nggak menular, Herman!"

"Kebiasaan makanmu yang bisa menular," Herman bergidik. (TM, 2020: 80)

Menurut mitos kecantikan, semua hal yang berhubungan dengan makan pada perempuan adalah sebuah isu publik. Porsi makan perempuan membenarkan dan memperkuat perasaan inferior secara sosial. Perempuan juga harus makan makanan yang berbeda dengan yang dimakan laki-laki (Wolf, 2017). Dalam novel Belok Kiri Langsing, terungkap bahwa penetapan standar kecantikan tidak hanya dikomunikasikan oleh tokoh laki-laki (Herman dan Dimas), tapi juga oleh tokoh perempuan (Elsa dan Julia) kepada tokoh utama. Sebagaimana dinyatakan Wolf, yang dikutip Anugrah (2015), "[...] perempuan akan tetap disalahkan karena penampilan mereka. Perempuan akan disalahkan oleh siapa saja yang merasa perlu untuk menyalahkan mereka."

"Memangnya pola makan aku seburuk apa?"

"Apa kamu nggak sadar? Setiap kita makan, kamu selalu pilih tiga porsi yang berbeda."

"Ya, biar kamu juga merasakan macam-macam menu, Man."

"Kenyataannya, kamu selalu menghabiskan semuanya, bahkan sebelum aku sempat nyicipin.” (TM, 2020: 44)

"Gen, berhenti ngarepin orang lain gemuk kayak lo,” tegas Elsa dengan serius. "Harusnya lo yang langsing kayak kita-kita.” $[\ldots]$

"Cape ah, tiap hari nyemangatin lo, ujung-ujungnya begitu turun lima kilo makannya segambreng lagi. Mending gue urus anak gue.” (TM, 2020: 63-64)

Kedua kutipan tersebut menunjukkan adanya intervensi dari tokoh-tokoh lain yang mengkritisi perilaku Gendis. Sebagaimana dinyatakan Wolf (2017), jika perempuan merasa penampilannya buruk, maka itu adalah kesalahan dirinya sendiri, sehingga dia tidak memiliki hak absolut untuk merasa cantik. Kebiasaan makan dan mengemil yang banyak, rasa malas berolahraga, dan sikap tidak peduli pada tubuh karena merasa sudah memiliki pasangan membuat Gendis sulit menurunkan berat badannya. Hal ini dipengaruhi oleh prinsipnya bahwa, "Makan adalah cara terbaik mengusir kesendirian." (hal. 85). Situasi tersebut menunjukkan bahwa mitos kecantikan selain dilanggengkan melalui sosialisasi nilai-nilai patriarki, juga terus menguat karena sifat ambivalen perempuan sendiri. Kondisi yang dialami Gendis seperti mengafirmasi stereotip yang melekat pada perempuan, yaitu tidak rasional karena senang makan/ mengemil tapi ingin memiliki tubuh yang langsing.

Laci pertama penuh cokelat aneka bentuk dan merek. Julia sama denganku, penggila cokelat. Laci kedua ada macam-macam Chiki, laci ketiga ada beberapa diet bar (yang nggak aku suka), jus kotak, aneka kacangkacangan, dan permen. Laci paling bawah, uhm, ini dia, keripik kentang kesukaanku dan Julia. [...]

Bedanya, laci Julia rapi dan tertata, sedangkan lemariku acak-acakan, yang penting semua masuk. (TM, 2020: II-I2)

Kesukaan perempuan dalam mengonsumsi makanan disebut Davidauskis (2015) bisa jadi merupakan bentuk resistensi, karena perempuan yang lapar menunjukkan kepemilikan hasrat dan perilaku asertif. Namun, sebagai dampak dari perilaku tersebut, Gendis menderita berbagai penyakit yang bersumber dari pola makannya yang tidak sehat. Selain sulit bergerak, ia juga mengalami hipertensi dan sering mengalami vertigo hingga harus menginap di klinik kesehatan. Berbagai upaya telah dilakukan Gendis untuk menurunkan berat badannya. Dengan bantuan tokoh Dimas dan Elsa, ia kemudian mengatur pola makannya, memperbanyak makan buah, dan minum air putih. Gendis juga berolahraga yoga dan aerobik. Anugrah (2015) mengutip pernyataan Wolf bahwa "[...] perempuan telah belajar untuk menyerah pada rasa sakit dengan mendengar suara dari figur-figur yang dianggap memiliki otoritas, yang menyatakan bahwa apa yang dirasakan itu bukan rasa sakit.”

Ya, berat badanku sudah turun $8 \mathrm{~kg}$ lagi dalam waktu dua minggu ini. Total diet selama dua bulan lewat dua minggu ini, berat badanku sudah turun $16 \mathrm{~kg}$. ini prestasi yang luar biasa untukku. Takkan terjadi tanpa bantuan Dimas. Setiap melihat timbangan ke kiri sedikit demi sedikit aku merasa mendapatkan kepingan- 
kepingan emas yang akan membuatku kaya raya. Namun ada kalanya aku merasa lelah, jiwa, raga, dan tubuhku meminta istirahat. (TM, 2020:276)

Keluhan perempuan terhadap tubuhnya tidak hanya berkaitan dengan aspek estetika tubuh melainkan juga gejala penyakit akibat obesitas yang mengganggu aktivitasnya. Gendis dikisahkan menderita hipertensi dan sering mengalami vertigo hingga harus menginap di klinik kesehatan. Wolf mengungkapkan tradisi pandangan Barat, bahwa perempuan adalah lelaki yang salah arah, lemah, dan tidak sempurna. Karena kelemahannya, perempuan selalu 'sakit', sehingga memberikan keuntungan yang besar pada para dokter" (Anugrah, 2015). Relasi di antara ketidakpuasan perempuan terhadap tubuhnya ini ditunjukkan dalam novel melalui produkproduk yang menunjang kecantikan, seperti obat pelangsing, minuman herbal tinggi protein untuk diet, katering diet, sanggar olahraga khusus perempuan, perlengkapan olahraga khusus perempuan, komunitas olahraga, hingga buku-buku tentang diet. Ketika perempuan tidak sanggup memenuhi standar kecantikan yang berlaku di dalam masyarakat, besar kemungkinan mereka akan merasa tidak nyaman, terasing, kesepian, dan kurang percaya diri (Wolf, 2004).

Dari pembahasan ini, terungkap bahwa perempuan kerap merasa tidak puas dengan kondisi tubuhnya karena standar yang diterapkan oleh masyarakat. Hal ini sejalan dengan kajian Kholmogorova dkk (2017), bahwa faktor sosial memainkan peran penting dalam pendistribusian standar kecantikan fisik dan kesehatan mental. Untuk dapat menyesuaikan diri dengan standar tersebut, perempuan pun merasa wajib untuk mendisiplinkan tubuhnya. Kondisi ini dimanfaatkan benar terutama oleh pihak industri sebagai representasi patriarki.

\section{Cara Mitos Kecantikan Bekerja dan Dampaknya pada Perempuan}

Wolf (2004-24) menjelaskan bagaimana mitos kecantikan menegaskan bahwa kualitas 'cantik' itu benar-benar ada secara objektif dan universal. Karena itu, setiap perempuan ingin menjadi 'cantik' dan laki-laki ingin memiliki perempuan yang 'cantik'. Laki-laki sebagai pihak yang berada dalam posisi memandang perempuan menciptakan batasan dan ukuran dalam konsep kecantikan. Dengan menggantikan bentuk patriarki lama, mitos kecantikan pun terbentuk dan terus menguat untuk mengintimidasi perempuan melalui berbagai jalan.

Dalam novel Belok Kiri Langsing, setidaknya ada tiga cara mitos kecantikan bekerja, yaitu melalui citra diri perempuan, body shaming, dan kompetisi intraseksual. Mitos kecantikan membuat tubuh yang berbeda dari standar normal perempuan (langsing) menjadi teralienasi.

Aku berlari kecil meninggalkan Herman kemudian berpapasan dengan salah satu peserta perempuan yang menumpang motor personel medis dari panitia. Perempuan bertubuh tambun dan penuh lemak di sana-sini. Hhh ... aku tertawa sinis. Pasti itu cewek malas yang pikirannya hanya makan saja. Aku bersyukur dianugerahi tubuh langsing, cantik, kulit putih, dan hidung mancung (TM, 2020: 6).

Kepercayaan diri yang sangat tinggi terhadap tubuh sendiri ternyata dapat menimbulkan interpretasi negatif tentang tubuh orang lain yang dianggap tidak ideal. Hinaan pernah dilontarkan Gendis pada seorang laki-laki lima tahun yang lalu, yang ternyata adalah Dimas. Kekerasan verbal seperti itu merupakan body shaming, yaitu penghinaan bentuk fisik orang lain yang tidak sesuai dengan standar sempurna yang ditetapkan publik (Sakinah, 2018). Karena bentuk tubuhnya, laki-laki ini dianggap tidak pantas sehingga terdiskriminasi dari lingkungannya. Ia pun terobsesi untuk menjadi ideal dengan melakukan olahraga secara ekstrim dan diet ketat.

Lelaki gemuk itu mendongak, lipatan lehernya berlapis-lapis, wajahnya memerah, hidungnya terlihat pesek dengan kedua pipi menyembul keluar. Aku nyaris tertawa, dia mengingatkanku pada tokoh Pao. Badan bulat dengan celana pendek yang memperlihatkan lipatan lemak di sana-sini. Iyuuuh, aku bergidik (TM, 2020: 6-7). 
Pada gilirannya, Gendis sendiri digambarkan mengalami body shaming karena berat tubuhnya yang terus bertambah. Kebosanan tokoh tersebut pada ejekan dan hinaan dari lingkungannya pun mendorongnya untuk melakukan perubahan ekstrim. Hal ini terjadi, sebagaimana dinyatakan Mulyana (2005), cara perempuan menilai tubuhnya sangat berkaitan dengan bagaimana lingkungan sosial dan budaya di luar dirinya menilai tubuh perempuan. Ia dipanggil 'Gendut', diejek "bengkak', 'boros makan', 'seperti karung beras', hingga dihakimi 'akan sukar hamil'. Tubuhnya yang gemuk pun diperangi dan dibenahi dengan berbagai cara untuk dapat terbebas dari beban yang disandangkan orang lain melalui pelabelan negatif. Gendis pun menguraikan setiap usaha yang telah dilakukan untuk mendisiplinkan tubuhnya, mulai dari diet tidak makan nasi, diet dengan mengatur jam makan, berpuasa, dan hanya minum air putih.

Mitos kecantikan bersikap lebih tegas pada perempuan bekerja. [Dengan kesadaran bahwa tubuhnya disorot] perempuan yang memiliki pekerjaan di luar rumah pada umumnya akan berusaha untuk tampil cantik di depan publik (Rukmawati, 20I5). Namun, dalam novel, terungkap bahwa pertambahan berat badan yang tidak terkendali justru membuat Gendis tidak lagi memperhatikan penampilannya dan cenderung asal-asalan saja dalam berpakaian. Sikap abai perempuan pada tubuhnya ini dapat dimaknai sebagai pemberontakan atau keputusasaan dalam mengikuti standar yang telah ditetapkan masyarakat.

Enam bulan yang lalu, kausku sempat kekecilan dan sempit di sana-sini. Habis kajian, Elsa dan Julia menarik ketiakku kencang. Spontan di bagian ketiak kausku robek karena sudah kekecilan. Alhasil, aku pulang memakai mukena kantor. Besoknya aku merengek ke Elsa buat pinjam uang, demi membeli kaus-kaus jumbo. Aku mengepak semua kaus yang kekecilan dan tak mau memakainya lagi (TM, 2020: 59-60).

Dalam konteks percintaan di dalam novel Belok Kiri Langsing, terungkap bahwa mitos kecantikan juga berdampak pada kompetisi intraseksual antarperempuan, yaitu persaingan di dalam mendapatkan [perhatian] lawan jenis. Situasi ini seperti mengafirmasi gagasan Wolf (2017) bahwa mitos kecantikan membuat perempuan saling mencurigai dan membangkitkan kecemburuan. Dari narasi novel tersebut, terungkap bahwa tokoh Julia yang selalu menyediakan cemilan untuk Gendis ternyata memiliki tujuan membuat perempuan saingannya itu bertambah gemuk. Julia rela berkorban dengan cara ikut mengonsumsi camilan sebanyak yang dihabiskan oleh Gendis. Ia juga bersedia menghabiskan waktu istirahatnya di malam hari untuk berolahraga demi membakar kalori di tubuhnya dari makanan yang ia dapatkan sepanjang siang. Demi memenuhi hasratnya memiliki Herman, Julia menutup peluang Gendis dengan cara memproses tubuhnya, sebagaimana dinyatakan Wolf, untuk menjadi perempuan yang dianggap ideal oleh laki-laki.

\footnotetext{
"Gue sengaja ngasih lo banyak camilan, supaya lo makin gendut karena gue tahu Herman nggak suka cewek gendut." $[\ldots]$

"Gendis, lo mau kan maafin gue?"

"Kasih tau gue, gimana caranya gue maafin orang yang niat menggendutkan gue selama I,5 tahun ini? Lo kasih gue camilan banyak-banyak, sementara lo diet mati-matian dan olahraga ekstrem tiap hari supaya body lo tetap langsing. Gimana caranya gue maafin orang yang sudah merencanakan merebut pacar gue selama I,5 tahun ini, Julia?" (TM, 2020: 184).
}

Persaingan di antara perempuan untuk menjadi cantik demi menyenangkan laki-laki ini sesuai dengan hasil kajian Julian (2016: 52), bahwa ada relasi di antara mitos kecantikan dengan kontestasi antarperempuan/intraseksual. Kecenderungan perempuan untuk mengutamakan penampilan fisik serta obsesinya untuk menjadi cantik dan menarik dilekatkan pada femininitas. Semakin sesuai tubuh pada gambaran ideal yang diajukan oleh mitos kecantikan, maka perempuan tersebut akan danggap cantik. Berbeda dengan Julia yang bertubuh langsing, tubuh Gendis yang gemuk membuatnya menjadi dianggap tidak cantik dan tidak feminin sebagai perempuan, sehingga tidak menjadi pilihan calon istri idaman bagi Herman. Mitos kecantikan dalam hal ini bekerja dengan cara membuat tokoh utama mengalami tindak diskriminasi, obsesi berlebihan, dan rasa tidak puas terhadap tubuhnya. 


\section{Fenomena Hijrah dan Representasi Perempuan Islami'}

Seperti yang dinyatakan dalam kajian Addini (2019), hijrah yang awalnya merupakan ritus personal mulai bergeser menjadi gerakan sosial. Pilihan pribadi tersebut dapat meluas karena adanya ajakan dan dorongan dari pihak eksternal. Sebagaimana dinyatakan dalam penelitian Musahadah dan Triyono (2019), ada dua motif bagi seseorang yang melakukan hijrah yaitu motif sebab dan motif harapan. Dalam konteks Gendis, dari pembahasan sebelumnya, terungkap bahwa tokoh ini melakukan hijrah agar menjadi pribadi yang lebih baik setelah diputuskan oleh kekasihnya, Herman. Seiring dengan keinginan spiritual, ia pun melakukan modifikasi fisik dengan cara menurunkan berat badan dan lebih memperhatikan tubuhnya. Ia berusaha mengikuti ajaran agama Islam, yang menentukan bahwa tubuh perempuan harus disembunyikan, yaitu karena tubuh perempuan dianggap sebagai sumber fitnah atau gangguan yang memancing hasrat seksual laki-laki (Hermawati, 2018).

"Gen ... gue yakin, mungkin ini saat yang tepat buat lo pakai jilbab," ujar Elsa menjelang akhir obrolan. [...] 'Tidak dikatakan seseorang itu beriman kalau Allah belum mengujinya.' Sekarang, lo harus membulatkan niat buat pakai jilbab. Rencana ini selalu lo tunda karena Herman. Sekarang lo dah putus, jadi apalagi yang lo tunggu? Mungkin kejadian ini karena Allah sudah pengin lihat lo nutup aurat."

Weni mengibas rambut sebahunya dengan gerakan tidak nyaman (TM, 2020: I29).

Seperti Gendis, Elsa pun dikisahkan menggunakan jilbab dan rajin mengikuti pengajian sejak bercerai dari suaminya yang berselingkuh. Situasi ini sejalan dengan pandangan Baharun (Fajriani, 2019), bahwa salah satu faktor pendorong hijrah adalah perasaan kosong dalam jiwa yang menimbulkan kejenuhan. Berkaitan dengan tubuh perempuan, fenomena hijrah dalam novel Belok Kiri Langsing ini juga menitipkan pesan pada pembaca [terutama perempuan] untuk menjaga tubuh yang diciptakanNya, dengan cara mengatur pola makan, berolahraga, dan menyayangi diri sendiri lewat perilaku memaafkan dan mendekatkan diri pada Sang Pencipta. Perilaku tersebut sesuai dengan pandangan Rachmiati dkk. (2018: I0) bahwa perempuan muslimah harus mengadopsi sifat qanaah, berani, jujur, dan menjaga perilakunya. Selain mengubah perilaku dan penampilan, perempuan yang berhijrah juga pada umumnya menjaga ibadahnya. Ia harus melaksanakan ibadah-ibadah wajib dan sunah untuk menyempurnakan akhlaknya. Dalam novel, tokoh perempuan sebagai calon istri juga dituntut harus dapat membaca Al Qur'an, agar kelak saat menjadi ibu, ia dapat membimbing anak-anaknya sesuai ajaran agama.

"Coba kamu baca Al-Fatihah," pintanya yang membuatku melongo. "Aku mau dengar, makhraj-nya bagaimana, kamu bisa ngaji atau nggak, dan sejauh mana aku harus mengajarimu membaca Al-Qur'an dengan tartil." (TM, 2020: 298).

Gendis yang sebelumnya sangat gemar menonton drama Korea mulai beralih mengisi waktu luangnya dengan mendengarkan murotal dan kajian-kajian di televisi. Kesepian dan kesedihan Gendis karena ditinggalkan Herman membuatnya sempat berpikir untuk bunuh diri. Namun, nasihat-nasihat dari Dimas membuatnya memahami kematian dengan cara berbeda. Ia pun bertekad untuk lebih mensyukuri kondisinya dengan memperbaiki kesalahan di masa lalu. Situasi ini menunjukkan keselarasan dengan penelitian Lyansari (2018) bahwa proses hijrah mengubah pola pikir individu dan menciptakan gaya hidup 'baru'.

"Kematian sudah ditentukan Allah. Namun Allah menugaskan kita untuk menjaga tubuh kita. Olahraga dan menjaga pola makan adalah ikhtiarnya, tawakkalnya tetap kepada Allah." [... "Dengan sehat, kita bisa ibadah dengan lebih khusyuk.” (TM, 2020:2I3).

Perubahan sikap maupun pandangan terhadap tubuh merupakan proses hijrah yang dijalani oleh Gendis. Tubuh yang kini tertutup, sehat, dan lebih terawat merupakan gambaran dari perempuan islami yang ditampilkan di dalam novel Belok Kiri Langsing. Semangat untuk selalu memperbaiki diri adalah hakikat dari motif harapan tokoh tersebut. Perspektif ini sejalan dengan hasil penelitian Putri dan Sulistyani (2018), bahwa 
"tubuh perempuan adalah perhiasan, tubuh dan bentuk tubuh tidak untuk ditampakkan, dan menjaga tubuh berarti menjaga agama”.

Para tokoh laki-laki pun menunjukkan kecenderungan untuk berhijrah yang diperlihatkan melalui keikutsertaan mereka pada kajian rutin di kantor. Alasan dari perubahan ini sesuai dengan pendapat Baharun (Fajriani, 2019) adalah sikap kritis dalam memandang kehidupan dan hasrat untuk mengamalkan ajaran agama. Dimas, misalnya, menunjukkan prinsipnya dengan cara menegur pasangan Herman dan Gendis yang berpacaran di restoran ayam gepreknya. Ia juga ditampilkan sebagai laki-laki yang menyayangi orang tuanya terutama ibunya. Dimas berusaha menghindari riba dan selalu menjaga etika dalam berbisnis. Ia pun memperlihatkan sikap menjaga adab saat bersama lawan jenis dengan cara tidak bersentuhan dan menghindari berada dalam ruang tertutup berduaan, termasuk pada sosial media. Ia juga memilih untuk tidak berpacaran dan cenderung ingin langsung menikah. Namun, pada sejumlah situasi ada kontradiksi yang ditunjukkan saat lakilaki tersebut seperti sedang merayu Gendis, yang bukan pasangannya, dengan kata-kata manis, sehingga 'kehijrahannya' pun menjadi diragukan. Hal ini menyiratkan kesesuaian situasi dengan gagasan Sholihah (2019) bahwa hijrah yang dilakukan muslim milenial masih terbatas pada kesalihan fisik dan belum benar-benar menyentuh hakikatnya.

"Dia cuma kenalan. Orang yang harus balas budi ke saya."

"Bukannya kita teman dekat, Gen?" sambar Dimas terlihat agak kecewa. (hal. 2I5)

"Aku juga bingung, Dim. Aku cuma ingin diet, ingin kurus tanpa bantuanmu."

"Oke ... kalau ini semua tentang rasa bersalah, lalu bagaimana kalau ada rasa yang lain?" (hal. 248)

"Cuma kamu yang aku anterin ini pagi-pagi," Dimas menunjuk karung. "Jangan jauh-jauh lagi dariku, Gen." (hal. 252)

Seperti Dimas, Herman juga menyatakan diri sedang berproses hijrah. Namun, seperti Dimas, pada Herman terungkap inkonsistensi di antara ucapan dan tindakannya. Ia berselingkuh dengan Julia dan bermesraan dengan perempuan itu di wilayah publik. Sikapnya saat memutuskan Gendis pun cenderung kasar dan memperlihatkan egoisme yang tinggi sebagai laki-laki yang berselingkuh.

Hal lain yang patut dikritisi dari fenomena hijrah dalam novel ini adalah wacana pernikahan yang ditawarkan Dimas setelah memecat Gendis dari perusahaan ayahnya. Laki-laki itu bahkan menjanjikan 'pekerjaan yang lebih baik dengan gaji dua puluh juta, rumah, dan mobil' yaitu dengan menjadi istrinya. Situasi ini menunjukkan betapa institusi perkawinan didegradasi oleh sang calon suami sebagai sebuah 'pekerjaan' bagi calon istri yang membuatnya berhak menerima 'upah'. Dengan kata lain, menjadikan Gendis sebagai istri dalam pandangan laki-laki yang sedang hijrah tersebut identik mendomestifikasi perempuan [kembali].

"Karena aku mau memberikan pekerjaan baru yang lebih layak buatmu."

"Berapa gajinya?"

"Dua puluh juta sebulan, beserta sebuah rumah dan isi, mobil dan sopirnya."

"Kerja sebagai apa?"

"Sebagai istriku." [...]

"Gendis menang banyak .... Uwoooh!” (TM, 2020: 3I9)

Lamaran yang terjadi di pesta pernikahan kakaknya pun seperti dipaksakan Dimas pada Gendis, namun hal itu justru dianggap 'indah' oleh mereka yang menyaksikannya. Dalam perspektif lain, lamaran seperti ini cenderung menyerupai sebuah perangkap, karena sebelumnya tidak ada pembicaraan apapun di antara keduanya. Meskipun orang tua Gendis dan orang tua Dimas telah bersepakat, tetap saja pernikahan seharusnya dibangun oleh kesepakatan di antara pihak yang akan menikah. Subjektivitas Gendis diabaikan karena dalam konstruksi sosial, perempuan yang baik adalah perempuan yang patuh. Hal ini sejalan dengan pandangan 
Paramaditha (2007), bahwa ada agenda untuk mengembalikan perempuan "pada kodratnya sebagai ibu dan istri”.

Fenomena hijrah yang ditemukan di dalam novel Belok Kiri Langsing merupakan subtema yang dikembangkan oleh Achi TM sebagai tambahan pesan moral pada pembaca selain tentang mitos kecantikan. Perhatian dan perawatan tokoh perempuan pada tubuh merupakan proses hijrah yang berpengaruh pada pembentukan karakter dan cara pandangnya terhadap kehidupan. Inkonsistensi dan perilaku para tokoh yang seperti tidak sesuai dengan prinsip keagamaan dapat ditafsirkan sebagai indikasi bahwa hijrah merupakan proses panjang yang terus-menerus berjalan.

\section{SIMPULAN}

Penelitian ini menunjukkan bentuk mitos kecantikan dalam novel Belok Kiri Langsing, yaitu tubuh langsing sebagai tubuh ideal dan sempurna dari perempuan. Mitos kecantikan tersebut bekerja dan menguat, selain karena disosialisasikan secara terus-menerus, juga karena ambivalensi karakter perempuan yang kerap tidak merasa puas dengan tubuhnya. Mitos kecantikan membawa dampak pada citra diri perempuan, tindakan body shaming, dan terjadinya kompetisi intraseksual. Fenomena hijrah merupakan subtema yang juga dikembangkan dan dikaitkan dengan tema tubuh perempuan. Meskipun dijumpai beberapa narasi yang tidak sesuai dengan prinsip hijrah, namun pengarang menyisipkan pesan-pesan dengan nada yang tidak menggurui. Dari analisis terungkap bahwa secara tidak langsung, fenomena hijrah menciptakan mitos kecantikan baru berupa standar 'perempuan islami'.

Penelitian ini memperlihatkan bahwa ada persepsi masyarakat patriarki yang tidak utuh tentang perempuan dan tubuhnya. Kecantikan fisik berupa tubuh langsing yang disosialisasikan sebagai sesuatu yang ideal hendaknya tidak mengikat dan menyudutkan perempuan. Adapun pengaturan dan perawatan tubuh sudah seharusnya dilakukan atas kesadaran perempuan sendiri dan ditujukan untuk kepentingannya sendiri, bukan untuk menyenangkan laki-laki.

Penelitian terhadap novel Belok Kiri Langsing maupun karya populer lainnya yang membahas tentang perempuan, mitos kecantikan, dan fenomena hijrah perlu diikuti oleh penelitian lanjutan untuk memperkaya variasi temuan. Peneliti merekomendasikan agar kekurangan di dalam penelitian ini dapat disempurnakan melalui kajian-kajian terhadap novel kontemporer lainnya dengan pendekatan kritik sastra feminis maupun pendekatan lain seperti sosiologi sastra, psikologi sastra, dan antropologi sastra.

\section{UCAPAN TERIMA KASIH}

Peneliti mengucapkan terima kasih pada tim editor dan reviewer Kembara: Jurnal Keilmuan Bahasa, Sastra, dan Pengajarannya yang telah memberi banyak masukan untuk perbaikan artikel ini serta kesempatan untuk penerbitan artikel ini.

\section{DAFTAR PUSTAKA}

Addini, A. (2019). Fenomena gerakan hijrah di kalangan pemuda muslim sebagai mode sosial. Journal of Islamic Civilization, I(2), I09-I I8. https:// doi.org/I0.33086/jic.vIi2.I3I3

Aini, F. N. (2018). Mitos kecantikan dalam masyarakat konsumsi. (Skripsi), Universitas Islam Negeri Walisongo, Semarang.

Anggraini, P. (2016). Citra tokoh perempuan dalam cerita anak indonesia (sebuah pendekatan kritik feminisme). Kembara: Jurnal Keilmuan Bahasa, Sastra, dan Pengajarannya (e-Journal), 2(I), 6776. https://doi.org/I0.22219/kembara.v2iI.404

Anugrah, A. (2015). Mitos kecantikan dalam cerpen Barbitch dan Lipstik Merah Tua karya Sagita Suryoputri (telaah kritik sastra feminisme). Jurnal Humanika, I5(3), I-I5. Retrived From http://ojs.uho.ac.id/index.php/HUMANIKA/article/view/583/pdf

Arimbi, D. A. (2013). Beauty east dan beauty west: Wacana kecantikan perempuan muslim dalam majalah perempuan muslim. (Laporan Penelitian), Universitas Airlangga, Surabaya. 
Arimbi, D. A. (2017). Women in Indonesia popular fiction: Romance, beauty, and identity politics in metropop novels. In M. A. Jan van der Putten, Edwin P. Wieringa and Arndt Graf (Ed.), Traditions Redirecting Contemporary Indonesian Cultural Productions (pp. 247-27I): Cambridge Scholars Publishing.

Arista, A. (2017). Kekerasan verbal berbasis gender dalam novel Nayla karya Djenar Maesa Ayu. Kembara: Jurnal Keilmuan Bahasa, Sastra, dan Pengajarannya (e-Journal), 3(2), I23-I34. https://doi.org/I0.22219/kembara.v3i2.513I

Davidauskis, A. (2015). "How beautiful women eat": Feminine hunger in American popular culture. Feminist Formations, 27(I), I67-I89. http:/ /dx.doi.org/I0.1353/ff.20I5.0005

Diba, F. (20I4). Aspek sosial dalam novel Bisikan Sahabat karya Achi TM. (Skripsi), Universitas Nusantara PGRI Kediri, Kediri.

Fajriani, S. W. S., Y. S. (2019). Hijrah islami milenial berdasarkan paradigma berorientasi identitas. Sosioglobal: Jurnal Pemikiran dan Penelitian Sosiologi, 3(2), 77-88. https://doi.org/I0.24I98/jsg.v3i2.21643

Fikkan, J. L. R., Esther D. (20I2). Is fat a feminist issue? Exploring the gendered nature of weight bias. Sex Roles, 66, 575-952. I0.1007/sI I I99-0II-0022-5

Hatmoko, W. (2019). Achi TM, penulis perempuan dengan ratusan karya imajiner. http://lensapena.id/2019/I2/achi-tm-penulis-perempuan-dengan-ratusan-karya-imajiner/ diakses tanggal 5 November 2020.

Hermawati, Y. (2018). Jilbab: Pengejawantahan tubuh individu dan tubuh sosial perempuan muslim. In A. P. d. L. Manggong (Ed.), Tubuh dan ideologi. Yogyakarta: Arti Bumi Intaran.

Humm, M. (2007). Ensiklopedia feminisme (M. Rahayu, Trans.). Yogyakarta: Fajar Pustaka Baru.

Intan, T. M., Prima Agustina. (2019). Membongkar mitos kecantikan dan budaya konsumen dalam novel Chick lit Beauty Case karya Icha Rahmanti. Sejarah dan Budaya, I3(2), I64-I78. r Retrived from http://journal2.um.ac.id/index.php/sejarah-danbudaya/article/view/8139/4995

Julian, R. (2016). Mitos kecantikan dalam cerpen-cerpen Dwi Ratih Ramadhany. Jurnal POETIKA, 4(I), 52-60. https://doi.org/I0.22I46/poetika.v4iI.I33I5

Kholmogorova, A. T., P.; Shalygina, O. (2017). Standards of physical beauty and mental health in children and young people in the era of the information revolution. International Journal of Culture and Mental Health, https://doi.org/I0.I080/I7542863.2017.1394007

Kurnianto, E. A. (20I4). Representasi tubuh dan kecantikan dalam tiga cerpen Intan Paramaditha: Sebagai sebuah tatanan simbolik dalam dunia perempuan. Metasastra, 7(I), 23-34.

Lyansari, K. N. (2018). Hijrah celebrity: Creating new religiosities, branding economics of lifestyle in the age of muslim mass consumption. Analisis: Jurnal Studi Keislaman, I8(2), 2II-232. https://doi.org/I0.24042/ajsk.vI8i2.3066

Moleong, L. J. (2012). Metode penelitian kualitatif. Bandung: Remaja Rosdakarya.

Mulyana, D. (2005). Ilmu komunikasi suatu pengantar. Bandung: Remaja Rosdakarya.

Musahadah, Z. S. T., S. (2019). Fenomena hijrah di Indonesia: Konten persuasif dalam instagram. Retorika: Jurnal Bahasa, Sastra, dan Pengajarannya, I2(2), II7-I27. https://doi.org/I0.26858/retorika.vI2i2.7874

Nasution, P. P. P. A. (2015). "Berpenampilan menarik" (sketsa budaya konsumerisme dan eksistensi perempuan di dunia kerja). Paper presented at the Seminar Nasional Ilmu Sosial dan Ilmu Politik: Gender Politik dan Pembangunan di Indonesia: Perspektif Multidisiplin, FISIP UNS.

Natha, G. (20I7). Representasi stereotipe perempuan dan budaya patriarki dalam video klip Meghan Trainor "All About That Bass". Jurnal E-Komunikasi Program Studi Ilmu Komunikasi Universitas Kristen Petra Surabaya, 5(2), I-9. Retrived from http://publication.petra.ac.id/index.php/ilmu-komunikasi/article/view/7073/6423 
Nugraha, D. S. (2019). On the beginning of modern Indonesian literature. Humanities \& Social Sciences Reviews, 7(6), 604-6I6. http://dx.doi.org/I0.18510/hssr.2019.769I

Paramaditha, I. (2007). Tracing the white ink: the maternal body in Indonesian women's writing. Review of Indonesian and Malaysian Affairs, 4I(2), 67-94. Retrived from https://search.informit.org/doi/abs/I0.3316/ielapa.963342653767702

Priyatna, A. (2018). Kajian budaya feminis tubuh, sastra, dan budaya pop. Yogyakarta: Arti Bumi Intaran.

Putri, R. U. S., Hapsari Dwiningtyas. (2018). Pemaknaan kecantikan perempuan pada group chat line alumni Pesantren Insan Cendekia Gorontalo. Interaksi Online, 7(I), I-8. Retrived from https://ejournal3.undip.ac.id/index.php/interaksi-online/article/view/22700

Rachmiati, A. S., Martono, Sanulita, H. (2018). Citra perempuan islam dalam novel Bumi Bidadari karya Taufiqurrahman Al-Azizy. Jurnal Pendidikan dan Pembelajaran Khatulistiwa, 7(8), I-I2. Retrived

from https://jurnal.untan.ac.id/index.php/jpdpb/article/view/27076/7567657768I

Rukmawati, D. R. D., Iskandar. (20I5). Konstruksi kecantikan di kalangan wanita karier (di Kecamatan Lamongan, Kabupaten Lamongan). Dimensi: Joumal of Sociology, 8(I), I-I6. Retrived from https://journal.trunojoyo.ac.id/dimensi/article/view/3722/2724

Sakinah. (2018). "Ini bukan lelucon": Body shaming, citra tubuh, dampak dan cara mengatasinya. Jurnal Emik, $\quad I(\mathrm{I}), \quad 53-67 . \quad$ Retrived from http:// ejournals.umma.ac.id/index.php/emik/article/view/4I/66

Sholihah, D. R. (2019). Trend berhijrah di kalangan muslim milenial. (Skripsi), Universitas Islam Negeri Sunan Ampel, Surabaya.

Silfia, M., R., Syahrul, dan Afnita. (2018). Permasalahan sosial dalam novel Di Batas Pelangi karya Achi TM. Diksi, 26(I), II-I7. https://doi.org/I0.2I83I/diksi.v26iI.22073

TM, A. (2020). Belok kiri langsing. Jakarta: PT. Gramedia Pustaka Utama

Wolf, N. (2004). Mitos kecantikan: Kala kecantikan menindas perempuan. Yogyakarta: Niagara.

Wolf, N. (2017). Mitos kecantikan: menafsir kecantikan dalam berbagai konteks (A. S. Witakania Sundasari, Trans. L. M. Rahayu Ed.). Bandung: Unpad Press. 